\title{
AVALIAÇÃO EXTERNA DOS CURSOS DE GRADUAÇÃO E DISCUSSÕES SOBRE DIVERSIDADE ÉTNICO-RACIAL E PROBLEMÁTICAS AMBIENTAIS
}

\author{
Giselle Soares Passos ${ }^{1}$ \\ Murilo Borges Silva ${ }^{2}$ \\ Suzana Ribeiro Lima Oliveira ${ }^{3}$ \\ Francisco Tomaz de Moura Júnior ${ }^{4}$ \\ Sandra Aparecida Benite Ribeiro ${ }^{5}$
}

\begin{abstract}
RESUMO: A educação superior brasileira é composta por um conjunto de instituições, públicas e privadas, que, em 2004, torna-se objeto de uma normatização federal (Lei $n^{\circ} 10.861$ ) cujo escopo é instituir o Sistema Nacional de Avaliação da Educação Superior (Sinaes). Tal sistema visa avaliar os cursos de graduação atribuindo-lhes um conceito que vai de 1 a 5 , sendo os conceitos $\leq 2$, insuficiente e os conceitos $\geq 3$, suficientes. Desse modo, a partir das metodologias descritas no artigo "Relato da metodologia geral de estudo do diagnóstico do ensino de graduação" do Instituto Nacional de Estudos e Pesquisas Educacionais Anísio Teixeira (Inep), dos relatórios das visitas in loco dos cursos de graduação e dos conceitos do Exame Nacional de Desempenho de Estudantes (Enade) da Universidade Federal de Goiás/Regional Jataí (UFG/REJ), buscou-se catalogar os conceitos dos cursos da referida instituição, apontando a forma como eles incorporam as discussões sobre a cultura afro-brasileira, o papel do negro na sociedade atual, além das problemáticas ambientais.
\end{abstract}

Palavras-chave: Avaliações externas. Cultura afro-brasileira. Questão ambiental.

\section{EXTERNAL EVALUATION OF UNDERGRADUATE COURSES AND REFLECTIONS ON ENVIRORNMENT AND ETHNIC RACIAL ISSUES}

ABSTRACT: Brazilian higher education comprises a set of public and private institutions, which became
the subject of a federal regulation $\left(\mathrm{n}^{\circ} 10.861 \mathrm{Law}\right)$ in 2004 , whose scope is to establish the National
System for the Evaluation of Higher Education (Sinaes). This system aims to evaluate undergraduate
courses by assigning them a concept ranging from 1 to 5 , where the concepts $\leq 2$ stands for insufficient
and the concepts $\geq 3$ for sufficient. Thus, based on the methodologies described in the article "Report on
the general methodology for diagnosis study on undergraduate education" of Anisio Teixeira National
Institute of Educational Studies and Research (INEP), the reports of on-site visits to undergraduate courses

${ }^{1}$ Doutorado e mestrado em Ciências pelo Departamento de Psicobiologia da UNIFEPS/EPM. Graduação em educação Física, pela Universidade de Franca. Professora no adjunto III na Regional Jataí - UFG. passos.gs@gmail.com

${ }^{2}$ Doutorando em História pela Universidade Federal de Uberlândia e mestre em História pela PUC-GO. Graduação em História UEG-GO. Professor na Regional Jataí - UFG. muriloborges.historia@ gmail.com

${ }^{3}$ Doutorado e em Geografia pela Universidade Federal de Goiás/IESA/Goiânia. Graduação em Geografia pela Regional Jataí - UFG. Professora da Regional Jataí - UFG. suzanarili@yahoo.com.br

${ }^{4}$ Pós-graduação em Geografia pela Regional Jataí - UFG. Graduação em Geografia pela Regional Jataí - UFG. fthomaz-junior@hotmail.com

${ }^{5}$ Pós-doutorado pela Universidade do Porto, FADEUP, Portugal, em Fisiologia. Doutorado e mestrado em Ciências Biológicas (Zoologia) pela Universidade Estadual Paulista Júlio de Mesquita Filho. Graduado em Ciências Habilitação em Biologia pela Universidade Estadual Paulista Júlio de Mesquita Filho. Professora da Regional Jataí UFG sandrabenite@gmail.com 
REVISTA ELETRÔNICA

DA GRADUAÇÃO/PÓS-CEADUUAÇÃO EMEDỦCAÇÃO UFG/REJ

and the National Student Achievement Examination (Enade) concepts of the Universidade Federal de Goiás/Regional Jataí (UFG/REJ), it was sought to catalog UFG/REJ's course concepts, pointing out the way they incorporate discussions about Afro-Brazilian culture, the role of the colored in today's society, as well as environmental issues.

Key-words: External Evaluations. Afro-Brazilian Culture. Environmental Issues.

\section{INTRODUÇÃO}

Criado pela Lei $\mathrm{n}^{\circ}$ 10.861, de 14 de abril de 2004 (BRASIL, 2004), o Sistema Nacional de Avaliação da Educação Superior (Sinaes) é formado por três componentes principais: a avaliação das instituições de nível superior, dos cursos e o desempenho dos estudantes. O Sinaes avalia todos os aspectos que giram em torno desses três eixos, principalmente o ensino, a pesquisa, a extensão, a responsabilidade social, o desempenho dos alunos, o corpo docente, as instalações e a gestão institucional.

O Instituto Nacional de Estudos e Pesquisas Educacionais Anísio Teixeira (Inep) é o órgão responsável por conduzir todo o processo/sistema de avaliação dos cursos de nível superior no Brasil, produzindo indicadores, e um sistema de informações (http://emec.mec.gov.br) que subsidia tanto o processo de regulamentação dos cursos, exercido pelo Ministério da Educação (MEC), como garante transparência acerca da qualidade da educação superior no Brasil.

Os instrumentos que subsidiam a produção de indicadores de qualidade são o Exame Nacional de Desempenho de Estudantes (Enade) e as avaliações dos cursos, in loco, realizadas por comissões de especialistas, designadas pelo Inep. De acordo com a Portaria $n^{\circ} 40$, de 12 de dezembro de 2007, art. 33-B (MINISTÉRIO DA EDUCAÇÃO, 2007), são indicadores de qualidade:

1. O Conceito Preliminar de Curso (CPC), instituído pela Portaria $n^{\circ} 4$, de 6 de agosto de 2008 (MINISTÉRIO DA EDUCAÇÃO, 2008a);

2. O Índice Geral de Cursos Avaliados da Instituição (IGC), instituído pela Portaria

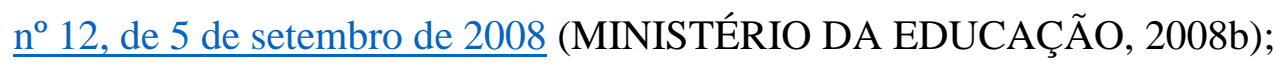

3. O conceito obtido a partir dos resultados do Enade;

Esses indicadores são expressos em escala contínua e em cinco níveis, nos quais os níveis iguais ou superiores a 3 (três) indicam qualidade satisfatória. 
REVISTA ELETRÔNICA

DA GRADUAÇÃO/PÓS-CEADUUAÇÃo EM EDÜCACĈ̃̃ UFG/REJ

Instituído pela Portaria $n^{\circ} 4$, de 5 de agosto de 2008, o conceito preliminar de curso (CPC), é um indicador de qualidade que integra diferentes indicadores: o Conceito do Enade; titulação e regime de trabalho do corpo docente; percepções dos estudantes sobre a organização didático-pedagógica, infraestrutura e as oportunidades de ampliação da formação acadêmica e profissional. O indicador somente é calculado para cursos que possuem ao menos dois concluintes, participantes no Enade. Quando o curso obtém conceito preliminar $\leq 2$, será avaliado pelo Inep.

As avaliações do Inep caracterizam-se pela visita in loco aos cursos de graduação de instituições públicas e privadas, e se destinam a verificar as condições de ensino, em especial aquelas relativas ao perfil do corpo docente, às instalações físicas e à organização didáticopedagógica. Os conceitos podem variar em uma escala com 5 (cinco) níveis (sendo que conceitos $>3$ indicam qualidade satisfatória).

No âmbito do Sistema Nacional de Avaliação da Educação Superior (Sinaes) e da regulação dos cursos de graduação no País, prevê-se que os cursos sejam avaliados periodicamente. Assim, os cursos de educação superior devem passar por três tipos de avaliação: para autorização, para reconhecimento e para renovação de reconhecimento.

O Enade possui como objetivo avaliar os alunos ingressantes e concluintes dos cursos de graduação, em relação aos conteúdos programáticos previstos nas Diretrizes Curriculares Nacionais, quanto ao desenvolvimento de competências e habilidades necessárias ao aprofundamento da formação geral e profissional, e acerca do nível de atualização dos estudantes, com relação à realidade brasileira e mundial.

Como citado anteriormente, foi a partir da publicação da Lei ${ }^{\circ} 10.861$, de 14 de abril de 2004 (BRASIL, 2004), que se iniciaram as avaliações das instituições de educação superior, dos cursos de graduação e do desempenho acadêmico de seus estudantes, no Brasil. Assim, os objetivos do presente estudo foram catalogar os conceitos dos cursos da Universidade Federal de Goiás, Regional Jataí (UFG/REJ) e sintetizar os relatórios do Inep de cada curso, bem como indicar como tais cursos estão inseridos nas discussões sobre a cultura afro-brasileira e o papel do negro, além das questões ambientais.

\section{MÉTODOS}


Para execução do presente estudo utilizou-se como base as metodologias gerais, descritas no artigo "RELATO DA METODOLOGIA GERAL DE ESTUDO DO DIAGNÓSTICO DO ENSINO DE GRADUAÇÃO” (MINISTÉRIO DA EDUCAÇÃO, 2017) do presente dossiê. Além disso, coletou-se dados dos relatórios das visitas in loco dos cursos, dos conceitos do ENADE no site do Inep (http://portal.inep.gov.br/web/guest/indicadores-de-qualidade) (MINISTÉRIO DA EDUCAÇÃO, [s.d.]).

\section{RESULTADOS E DISCUSSÃO}

O prognóstico realizado na UFG/Regional Jataí, identificou, a partir dos relatórios das visitas in loco, qualidade satisfatória dos cursos, com média de 3,7 no indicador conceito de curso (Figura 1).

Cabe ressaltar que não conseguimos avaliar alguns cursos, por não conseguir localizar o relatório de avaliação in loco. Alguns porque são cursos novos (como é o caso do Curso de Medicina), e outros porque obtiveram conceito preliminar maior que 2, e portanto, não foram selecionados para receber avaliação in loco para renovação de reconhecimento, após 2004.

$\mathrm{Na}$ análise dos Conceitos Preliminares de Curso (CPC) identificamos média de 3,4 (Figura 2). Cabe ressaltar que alguns cursos estão sem conceito, são eles: Direito, Engenharia Florestal, Letras inglês, Medicina, Enfermagem, Fisioterapia, Educação Física - Bacharelado e Química - Bacharelado. Alguns cursos não possuem esse conceito porque são cursos que ainda não haviam sido reconhecidos no momento da avaliação (estavam sem Portaria aprovada), e outros porque são cursos novos.

Figura 1. Conceitos dos Cursos de Graduação da UFG/Regional Jataí. 

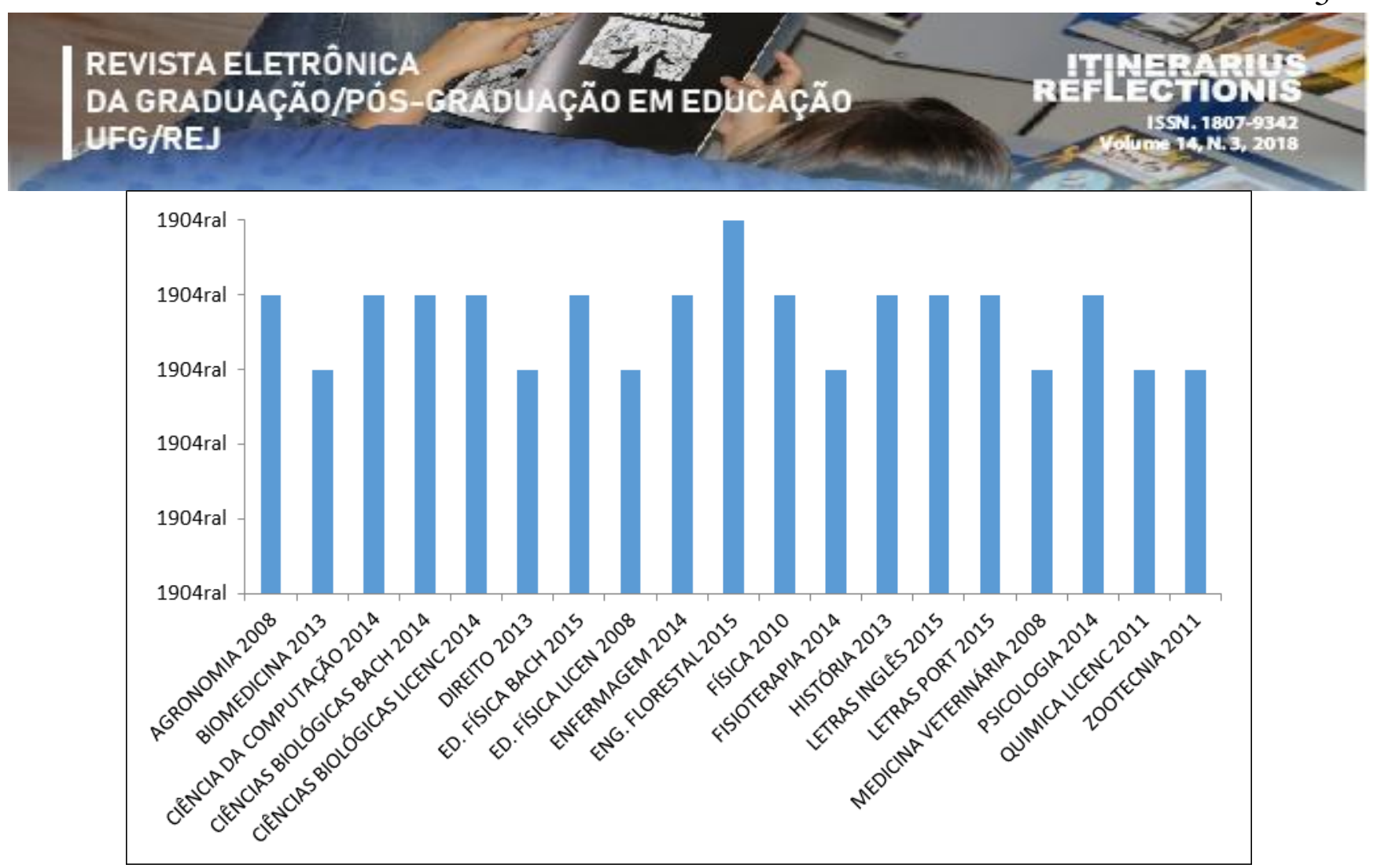

Fonte: Relatórios das avaliações in loco, do Inep. Organização: GT Ensino: Currículo e Avaliação, 2018.

Figura 2. Conceito Preliminar de Curso (CPC) dos Cursos de Graduação da UFG/Regional Jataí.

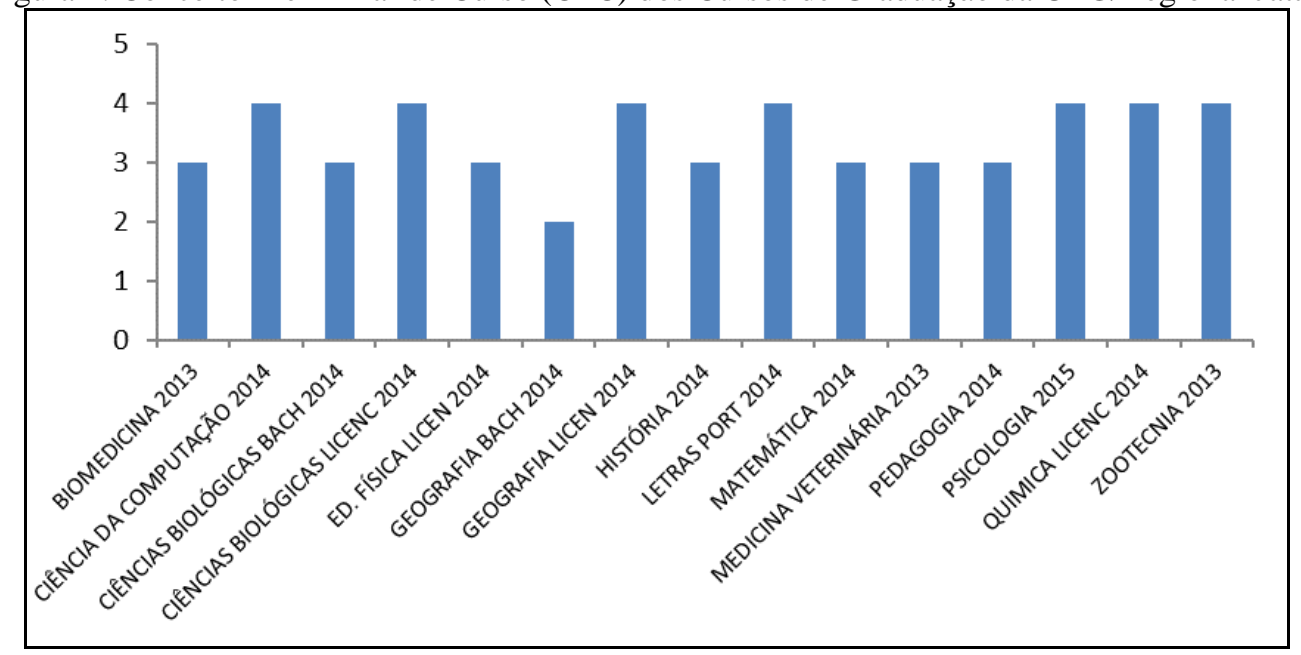

Fonte: Portal do Inep (http://portal.inep.gov.br/conceito-preliminar-de-curso-cpc-). Organização: GT Ensino: Currículo e Avaliação, 2018.

Quando comparada às outras regionais, Jataí tem apresentado crescimento ao longo dos anos, no CPC geral. Como pode-se observar, o CPC atual é maior quando comparado à Regional Catalão (Figura 3). Além disso, os cursos de licenciatura apresentam crescimento ao longo dos anos, enquanto os cursos de bacharelado obtiveram decréscimo (Figura 4). 
REVISTA ELETRÔNICA

DA GRADUAÇÃO/PÓS-CEADUAÇÃO EMEDÜCAÇÃO UFG/REJ

Figura 3. Média do Conceito preliminar de Curso (CPC) por ano/Regional da UFG.

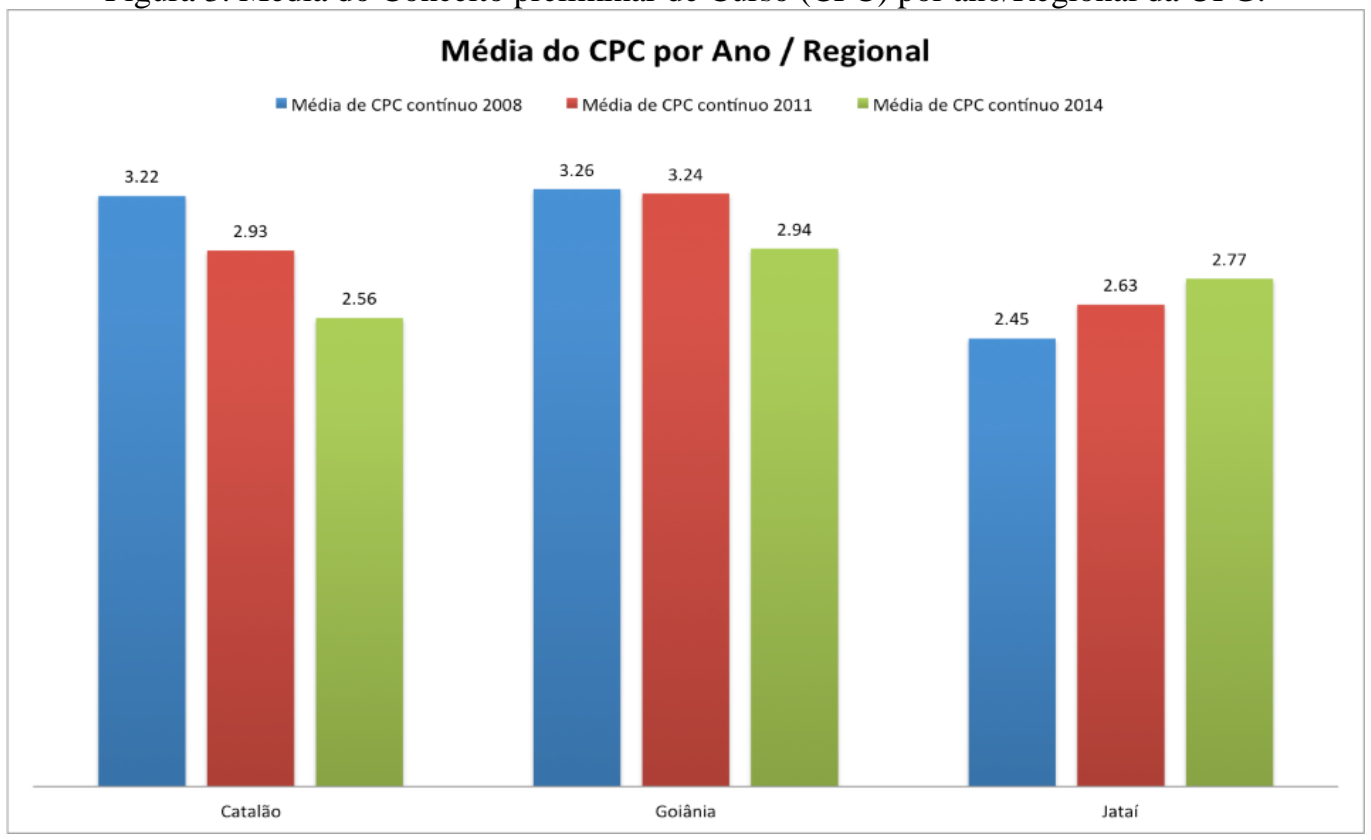

Fonte: PROGRAD, 2018.

Figura 4. Média do Conceito preliminar de Curso (CPC) da UFG/Regional Jataí (Licenciatura/Bacharelado)

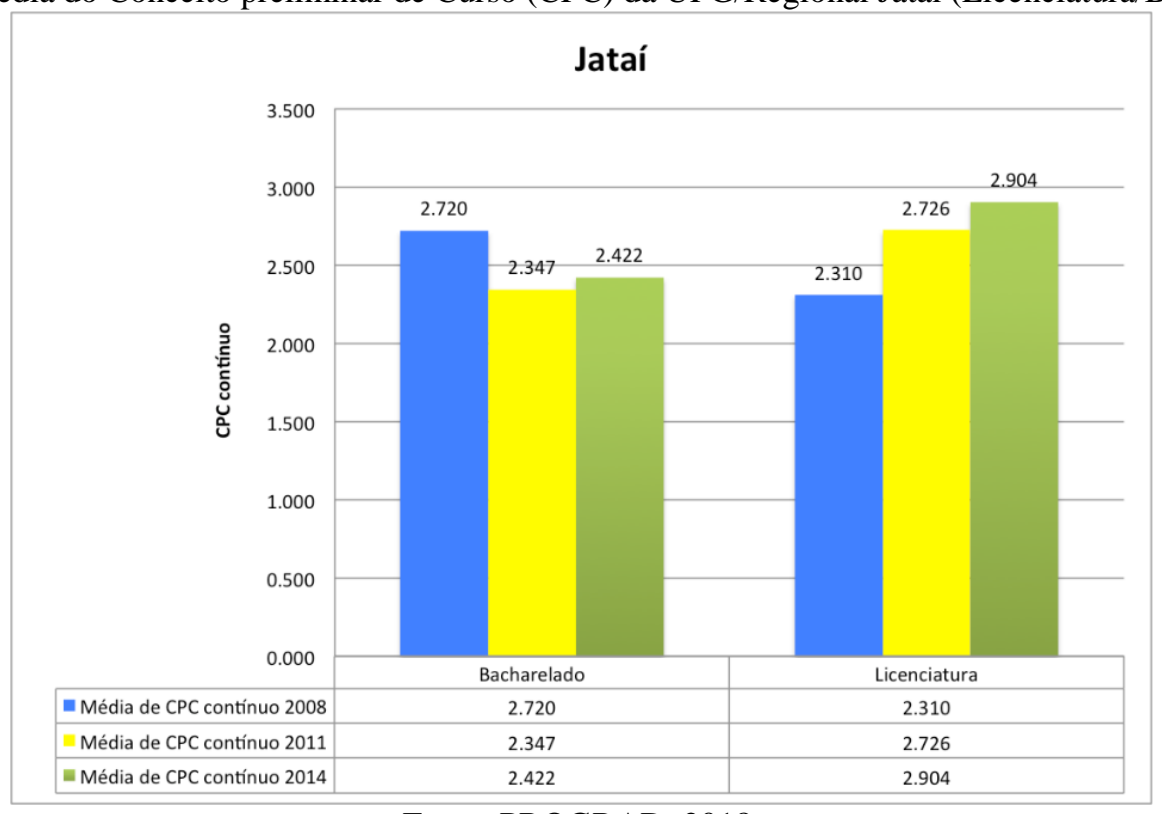

Fonte: PROGRAD, 2018.

$\mathrm{Na}$ avaliação do ENADE, a média geral dos cursos de graduação foi 3,4 (Figura 5). Cabe ressaltar que dois cursos tiveram nota abaixo de 2 (dois), os Cursos de Matemática e Geografia Bacharelado. Alguns cursos não possuem nota do Enade: Medicina, Fisioterapia e Química - 
REVISTA ELETRÔNICA

DA GRADUAÇÃO/PÓS-CEADUAÇÃo EM EDJ̈CAÇÃ̃o UFG/REJ

Bacharelado, devido ao fato de serem cursos recentes e não terem uma primeira turma concluída, como é o caso do curso de Medicina.

Figura 5. Conceito Enade dos Cursos de Graduação da UFG/Regional Jataí.

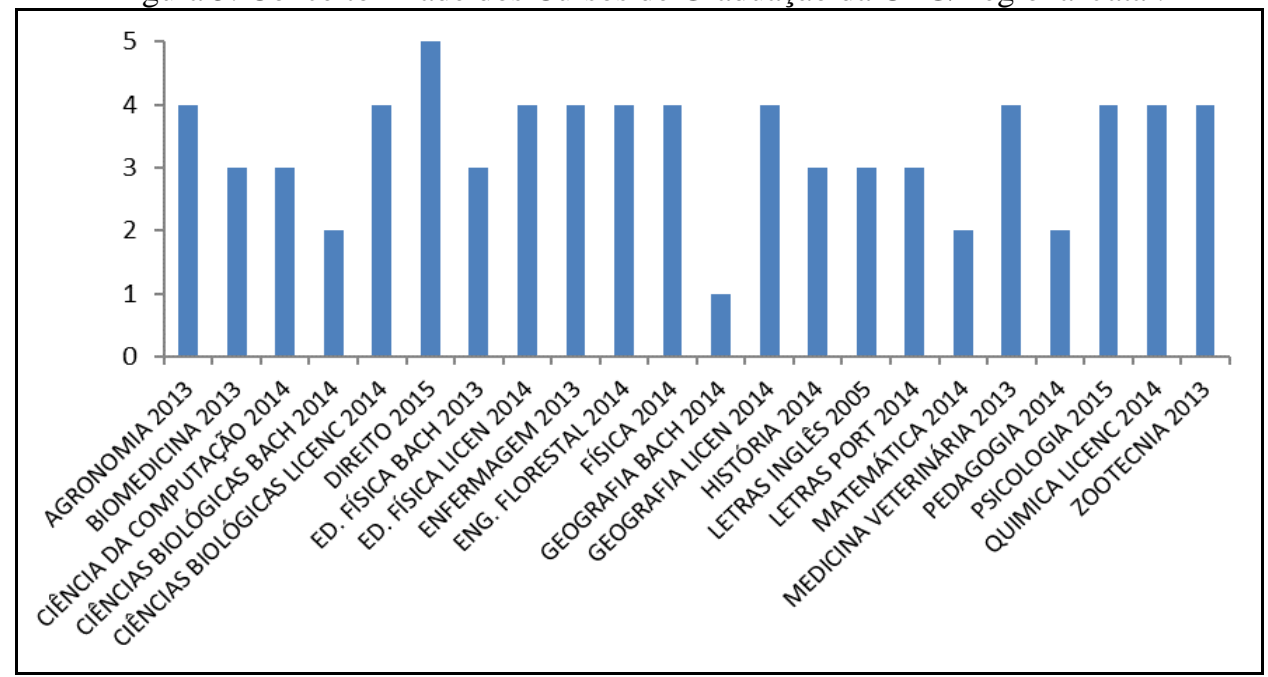

Fonte: Portal do Inep (http://portal.inep.gov.br/web/guest/conceito-enade). Organização: GT Ensino: Currículo e Avaliação, 2018.

A dimensão “organização didático-pedagógica”, busca avaliar a administração acadêmica dos cursos: a coordenação, a organização técnica e administrativa, a atenção aos discentes e a proposta dos cursos em si mesmas: concepção, conteúdos curriculares, sistema de avaliação, estando dispostas nas seguintes fontes de consulta: Plano de Desenvolvimento Institucional, Projeto Pedagógico do Curso, Relatório de Autoavaliação Institucional, Políticas Institucionais, Diretrizes Curriculares Nacionais, quando houver, Catálogo Nacional dos Cursos Superiores de Tecnologia, quando couber, Formulário Eletrônico preenchido pela IES no e-MEC (Art. $1^{\circ}$ da Portaria Normativa 40/2007, consolidada em 29 de dezembro de 2010, para aplicação dos indicadores) (MINISTÉRIO DA EDUCAÇÃO, 2007).

$\mathrm{Na}$ REJ, a organização didático-pedagógica possui uma média de 3,7, existindo cursos com média 5 e cursos com média 3, conforme podemos observar na Figura 6.

A presente dimensão tem como referências as políticas institucionais de ensino, de extensão e de pesquisa no âmbito dos cursos. Na REJ, a média é de 3,8, existindo cursos com 5 e cursos com média 1, conforme Figura 7. 


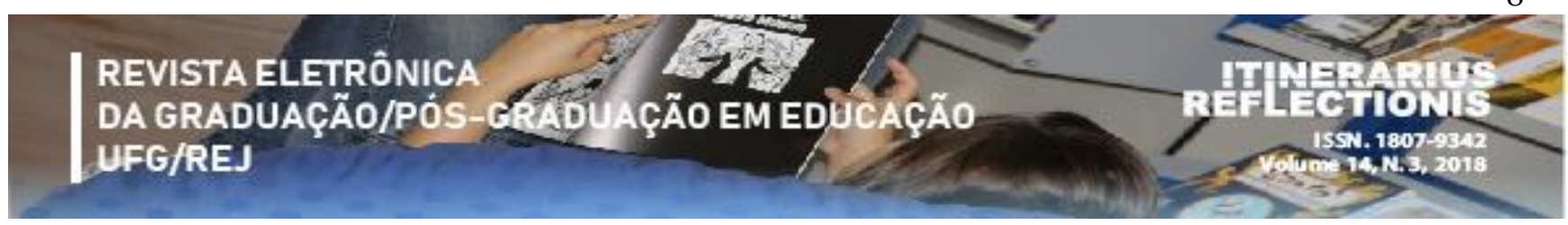

Figura 6. Organização Didático-Pedagógica.

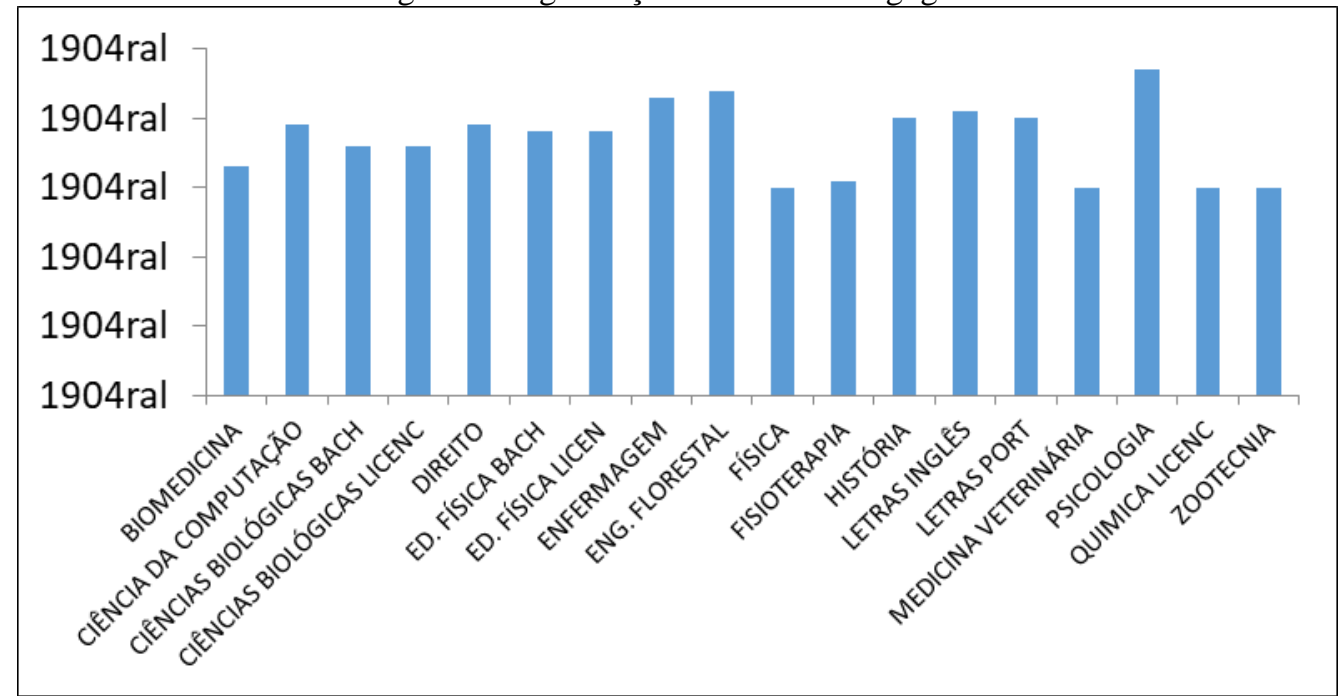

Fonte: Relatórios das avaliações in loco, do Inep. Organização: GT ensino, 2017.

Figura 7: Políticas Institucionais de Ensino, Pesquisa e Extensão.

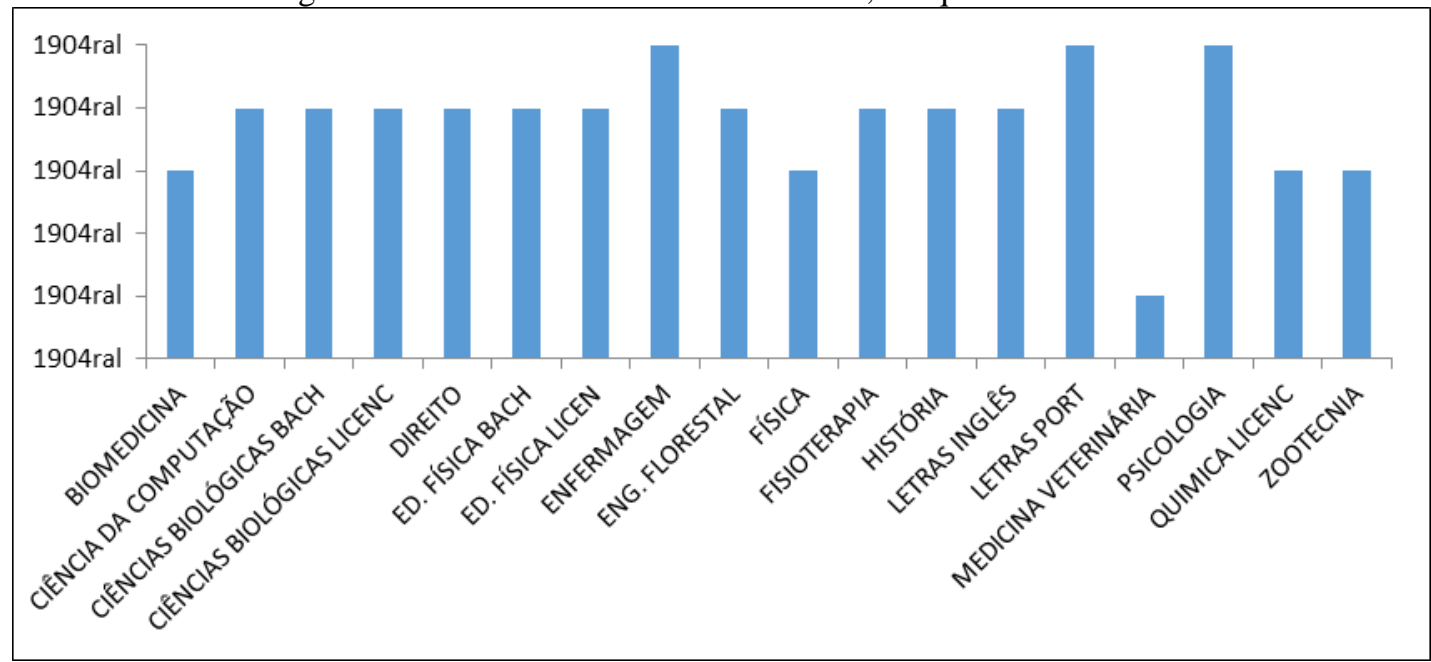

Fonte: Relatórios das avaliações in loco, do Inep. Organização: GT ensino, 2017.

Em relação à dimensão sobre as Diretrizes Curriculares Nacionais foram elaboradas com base nas orientações do CNE/CES e que devem ser necessariamente respeitadas por todas as instituições de ensino superior. Nesse sentido, o parecer CNE/CES n 776/97 (MINISTÉRIO DA EDUCAÇÃO e CONSELHO NACIONAL DE EDUCAÇÃO, 1997), visando assegurar a flexibilidade e a qualidade da formação oferecida aos estudantes, dispuseram sobre os princípios norteadores que são: 


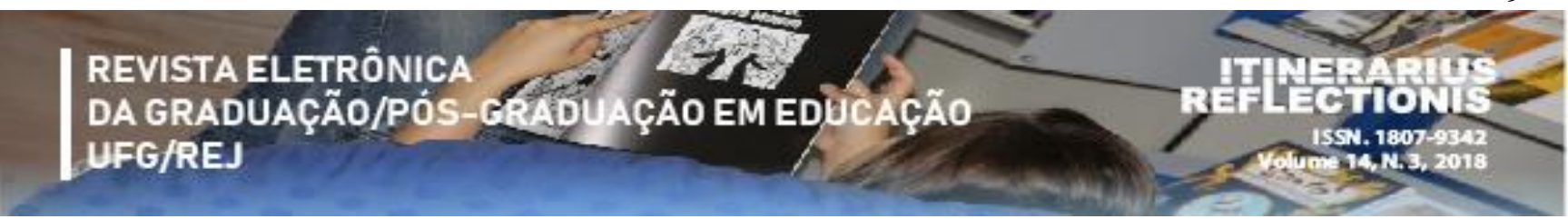

1) Assegurar às instituições de ensino superior ampla liberdade na composição da carga horária a ser cumprida para a integralização dos currículos, assim como na especificação das unidades de estudos a serem ministradas; 2) Indicar os tópicos ou campos de estudo e demais experiências de ensino-aprendizagem que comporão os currículos, evitando ao máximo a fixação de conteúdos específicos com 3 cargas horárias pré-determinadas, as quais não poderão exceder $50 \%$ da carga horária total dos cursos; 3) Evitar o prolongamento desnecessário da duração dos cursos de graduação; 4) Incentivar uma sólida formação geral, necessária para que o futuro graduado possa vir a superar os desafios de renovadas condições de exercício profissional e de produção do conhecimento, permitindo variados tipos de formação e habilitações diferenciadas em um mesmo programa; 5) Estimular práticas de estudo independente, visando uma progressiva autonomia profissional e intelectual do aluno; 6) Encorajar o reconhecimento de conhecimentos, habilidades e competências adquiridas fora do ambiente escolar, inclusive as que se referiram à experiência profissional julgada relevante para a área de formação considerada; 7) Fortalecer a articulação da teoria com a prática, valorizando a pesquisa individual e coletiva, assim como os estágios e a participação em atividades de extensão; 8) Incluir orientações para a condução de avaliações periódicas que utilizem instrumentos variados e sirvam para informar a docentes $\mathrm{e}$ a discentes acerca do desenvolvimento das atividades didáticas (MINISTÉRIO DA EDUCAÇÃO e CONSELHO NACIONAL DE EDUCAÇÃO, 1997).

Para a análise quanto às Diretrizes na REJ, foi identificado que $89 \%$ dos cursos de graduação para a elaboração dos projetos políticos pedagógicos, tem como referencial as DCNs. Sendo que alguns cursos não existem diretrizes específicas para os mesmos.

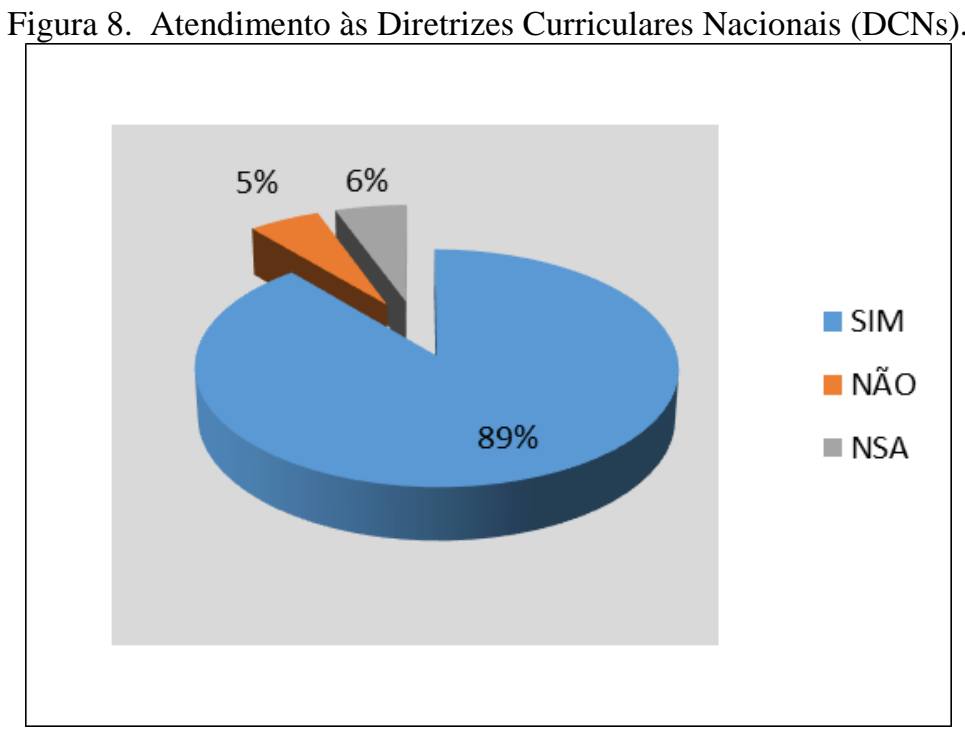

Fonte: Relatórios das avaliações in loco, do Inep. Organização: GT Ensino: Currículo e Avaliação, 2017.

Assim, percebe-se a grandeza dos desafios que se colocam à educação superior brasileira nas primeiras décadas do século XXI, em que, deve-se aliar ditames mais gerais, especificamente, 
REVISTA ELETRÔNICA

DA GRADUAÇÃO/POS-CEADUAÇÃo EM EDÜCAÇC̃̃o UFG/REJ

aqueles relacionados a qualidade do ensino público com demandas de grupos sociais e minorias políticas devido, principalmente, a organização e mobilização de grupos e movimentos sociais, o surgimento de novas demandas e a retomada de outras que, colocam para as IES, bem como para a sociedade, em geral, novos desafios. Pode-se destacar a inclusão das discussões sobre a relação África-Brasil, o processo de formação socioterritoral brasileiro e a escravidão, a cultura afrobrasileira, além de demandas de cunho ambiental, nas agendas universitárias.

Com isso, tem-se observado um eminente interesse em estudos e discussões que versem sobre África, agência de escravos/as e as contribuições da população negra na formação cultural, social e política do Brasil. Essas discussões - fomentadas pela atuação do Movimento Negro Brasileiro, de organizações, compostas, em sua maioria, por negros/as e estudiosos/as possibilitaram a implantação de políticas de ações afirmativas em diversos âmbitos, particularmente, na educação. O estabelecimento de cotas raciais em universidades públicas, por exemplo, faz parte desse contexto. Do mesmo modo, a publicação da Lei 10.639/03 configura-se como uma resposta do estado brasileiro às demandas da população negra no Brasil (BRASIL, 2003).

O texto da lei, que altera a Lei de Diretrizes e Bases da Educação, exige que conteúdos referentes à História e Cultura Afro-brasileira sejam ministrados no âmbito de todo o currículo escolar. Inclui a História da África e dos africanos, bem como, a cultura negra no Brasil como conteúdos programáticos a serem desenvolvidos, especialmente, nas disciplinas de História, Educação Artística e Literatura Brasileira. Por fim, institui, no calendário escolar, o dia 20 de novembro como Dia Nacional da Consciência Negra.

Embora importe, a lei recebeu algumas críticas. Foi considerada vaga e limitadora em diversos aspectos. A menção às disciplinas em que a lei seria, preferencialmente trabalhada, constitui-se uma dessas críticas. Além disso, muito se questionou sobre a ausência de diretrizes, materiais didáticos, de apoio e de estudos sobre a temática. Da mesma forma, argumentava-se sobre a falta de formação adequada para professores/as poderem cumprir a legislação. A publicação das Diretrizes Curriculares Nacionais para a Educação das Relações Étnico-Raciais e para o Ensino de História e Cultura Afro-Brasileira e Africana atenuaram, em parte, estes problemas. 
REVISTA ELETRÔNICA

DA GRADUAÇÃO/POS-CEADUAÇÃo EM EDÜCAÇC̃̃o UFG/REJ

Ademais, o texto das Diretrizes enfatizava a necessidade das instituições de ensino de fiscalizarem para que, no seu interior, os alunos negros deixem de sofrer os primeiros e continuados atos de racismo de que são vítimas (BRASIL, 2003). Ou seja, a legislação não deve ser pensada apenas como meio de divulgação de conhecimento sobre determinado tema, mas, e talvez o mais importante, ela deve ser um mecanismo de formação de cidadãos que possam atuar democraticamente e compreender as relações sociais e étnico-raciais que o circundam.

No âmbito do ensino superior, a redação dada pelo texto das referidas Diretrizes estabelece a obrigatoriedade de inclusão "nos conteúdos de disciplinas e atividades curriculares dos cursos que ministram, a Educação das Relações Étnico-Raciais, bem como o tratamento de questões e temáticas que dizem respeito aos afrodescendentes [...]"(Brasil, 2003). Nesses mesmos termos, definiu-se que o cumprimento das Diretrizes passaria a ser considerado na avaliação dos cursos em funcionamento nessas instituições.

Em 2008, a Lei 11.645 altera a Lei 9.394/1996 (Brasil, 2008), que já havia sido modificada pela Lei 10.639/03, acrescentando a obrigatoriedade dos estudos sobre história e cultura indígena. Torna-se, então, obrigatório, nas instituições de ensino no país, o estudo da história e cultura afro-brasileira e indígena (Brasil, 2008).

Assim, o Instrumento de Avaliação de Cursos de Graduação passa a cobrar, como requisitos legais e normativos, o cumprimento das Diretrizes. Utilizando-se dos relatórios, produzidos por essas avaliações, construímos o diagnóstico que se segue. Nele podemos perceber que os cursos de graduação da Regional Jataí atendem, parcialmente, as Diretrizes Curriculares Nacionais para Educação das Relações Étnico-Raciais e para o Ensino de História e Cultura Afro-Brasileira, Africana e Indígena, conforme demonstrado na Figura 9.

Figura 9. Atendimento às Diretrizes Curriculares Nacionais para Educação das Relações Étnico-Raciais e para o Ensino de História e Cultura Afro-Brasileira, Africana e Indígena. 

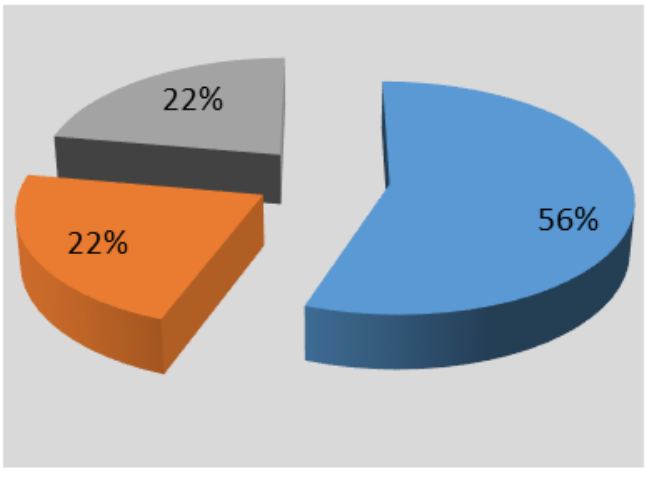

$\operatorname{SIM}$

nÃO

BRANCO

Fonte: Relatórios das avaliações in loco, do INEP. Organização: GT Ensino: Currículo e Avaliação, 2017.

Como pode-se observar, $56 \%$ dos cursos considerados neste estudo, possuem, segundo a avaliação realizada pelo Inep, alguma atividade que contemple as Diretrizes Curriculares Nacionais para Educação das Relações Étnico-Raciais e para o Ensino de História e Cultura Afro-Brasileira, Africana e Indígena. Os outros $44 \%$ dividem-se, igualmente, entre cursos que não cumprem as Diretrizes ou não possuem informações a respeito.

A implantação das Diretrizes Curriculares Nacionais para Educação das Relações ÉtnicoRaciais e para o Ensino de História e Cultura Afro-Brasileira, Africana e Indígena ainda é um desafio para muitas instituições de ensino superior no país. Esbarra-se em problemas diversos como: falta de professores/as especialistas no tema, ausência de centros de acolhimento a vítimas de discriminações étnico-raciais, de cursos de capacitação para docentes, carência de ações de extensão que contemplem as discussões propostas pelas Diretrizes, pouco estímulo para a criação de núcleos de estudos que envolvem a temática, timidez em ações para coibir práticas de racismo e qualquer outro tipo de discriminação, cobrança efetiva para que os cursos de graduação cumpram as Diretrizes, entre outros.

Do mesmo modo e de forma transversal aos desafios colocados para a real inclusão do negro, indígena e outras minorias políticas na universidade, colocam-se outros desafios que envolvem a Educação Ambiental e a Política Nacional de Educação Ambiental, conforme a resolução CNE/CP No 2/2012 (MINISTÉRIO DA EDUCAÇÃO, 2012), e disposto na Lei N $^{\circ}$ 9.795/1999 (BRASIL, 1999), no Decreto N 4.281/2002 (BRASIL, 2002), estabelece os seguintes objetivos: 
I - sistematizar os preceitos definidos na citada Lei, bem como os avanços que ocorreram na área para que contribuam com a formação humana de sujeitos concretos que vivem em determinado meio ambiente, contexto histórico e sociocultural, com suas condições físicas, emocionais, intelectuais, culturais;

II - estimular a reflexão crítica e propositiva da inserção da Educação Ambiental na formulação, execução e avaliação dos projetos institucionais e pedagógicos das instituições de ensino, para que a concepção de Educação Ambiental como integrante do currículo supere a mera distribuição do tema pelos demais componentes; III - orientar os cursos de formação de docentes para a Educação Básica; IV - orientar os sistemas educativos dos diferentes entes federados (BRASIL, 2008).

Para o diagnóstico da UFG/Regional Jataí, quanto a Educação Ambiental, foram analisados os Relatórios das Avaliações in loco, do Inep, dos cursos chegando ao indicador de cinquenta por cento $(50 \%)$ que possuem componentes em uma perspectiva reflexiva para a temática (Figura 9). Os demais cursos não explicitam se existe alguma ação que envolve a temática.

A seguir elencamos algumas ações que perpassam a reflexão quanto à Educação Ambiental, sendo elas:

- Contribuir, por meio de pesquisas e da prática didático-pedagógica, com reflexões/ações socioambientais.

- Realizar estudos e pesquisas que contribuam para o processo de discussão e construção do conhecimento socioambiental local, regional e global, formalizando ações de divulgação e utilização;

- $\quad$ Estabelecer parceria com outros grupos, instituições e representações interessadas nas questões educacionais socioambientais, bem como as secretarias do meio ambiente municipal, estadual e federal;

- $\quad$ Prestar consultoria em Educação Ambiental a empresas públicas bem como as escolas e colégios da região;

- Produzir materiais didático-pedagógicos de fundamentação teórico-prática em Educação Ambiental visando cooperar para a melhoria da qualidade de vida da população.

Figura 10. Atendimento à Política Nacional de Educação Ambiental, conforme a resolução CNE/CP Nº 2/2012. 

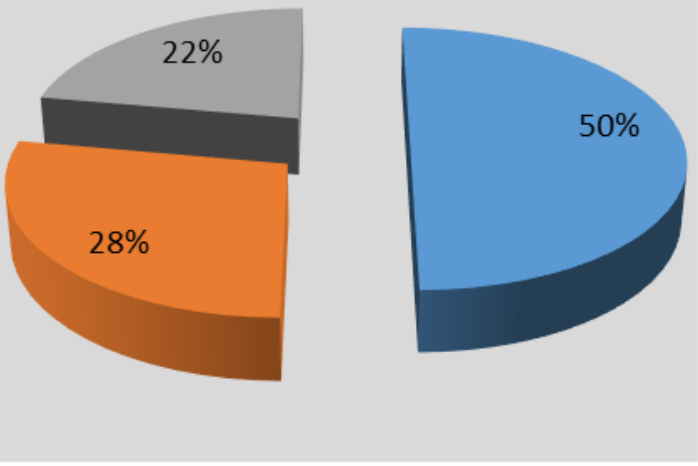

- SIM

- NÃO

BRANCO

Fonte: Relatórios das avaliações in loco, do INEP. Organização: GT Ensino: Currículo e Avaliação, 2017.

\section{CONSIDERAÇÕES FINAIS}

Diante das reflexões tecidas até aqui, pode-se apontar o esforço por parte dos órgãos gestores da educação superior no Brasil em instituir um Sistema Nacional de Avaliação da Educação Superior (Sinaes), de modo que, buscando articular diversos componentes como: o Conceito Preliminar de Curso (CPC), o Índice Geral de Cursos Avaliados da Instituição (IGC), o conceito obtido a partir dos resultados do Enade, além das visitas in loco tenta promover uma avaliação de aspectos não apenas quantitativos, mas também qualitativos.

Nesse contexto, a UFG/Regional Jataí apresenta um significativo envolvimento, havendo, contudo, cursos que ainda não foram avaliados e aqueles que obtiveram conceitos insuficientes ( $\leq$ 2). Tal cenário é ainda mais representativo quando comparado o CPC com outras regionais da UFG, sendo o valor atual superior ao desempenho da Regional Catalão.

A incorporação dessas normativas, todavia, colocam novos desafios para o ensino público superior como a inclusão nas pautas de discussão, nos projetos políticos pedagógicos dos cursos (PCC), nos regimentos universitários e em outros documentos que regem a tríade ensino, pesquisa e extensão.

Dentre essas normativas, destacamos a inclusão do papel do negro e do indígena na sociedade atual, inclusive na construção de um ensino superior democrático, a cultura afrobrasileira, a cultura indígena, além de demandas atuais como a questão ambiental e o desenvolvimento de outra racionalidade que não a capitalista. 
REVISTA ELETRÔNICA

DA GRADUAÇÃO/PÓS-CEADUAÇÃO EM EDỦCACÇ̃̃o UFG/REJ

Todas essas discussões, por exemplo, se fazem ainda mais necessárias à UFG/Regional Jataí, especialmente num momento, em que é sancionada a Lei $\mathrm{n}^{\circ} 13.635$, de 20 de março de 2018, responsável pela emancipação por desmembramento da UFG/Regional Goiânia, transformando-a em uma universidade autônoma, Universidade Federal de Jataí (UFJ).

\section{REFERÊNCIAS BIBLIOGRÁFICAS}

BRASIL. Lei no 9.795, de 27 de Abril de 1999., 1999.

BRASIL. Lei no 10.639, de 9 de Janeiro de 2003., 2003.

BRASIL. Lei no 10.861, de 14 de Abril de 2004., 2004.

BRASIL. Lei n⿳ 11.645, de 10 de Março de 2008, 2008.

BRASIL. Lei no 13.635 de 20 de Março de 2018, 2018.

BRASIL. Decreto $n^{0}$ 4.281, de 25 de Junho de 2002., 2002.

MINISTÉRIO DA EDUCAÇÃO. INEP - Indicadores de Qualidade dos cursos. Disponível em: 〈http://portal.inep.gov.br/web/guest/indicadores-de-qualidade〉.

MINISTÉRIO DA EDUCAÇÃO. Metodologia de cálculo dos indicadores de fluxo da Educação Superior. Brasília: INEP, 2017.

MINISTÉRIO DA EDUCAÇÃO. Resolução nº 2, de 15 de Junho de 2012, 2012.

MINISTÉRIO DA EDUCAÇÃO. Portaria Normativa $\mathbf{n}^{0}$ 40, de 12 de Dezembro de 2007, 2007.

MINISTÉRIO DA EDUCAÇÃO. Portaria Normativa n⿳0 04 de 06 de Agosto de 2008, 2008 a. MINISTÉRIO DA EDUCAÇÃO. Portaria Normativa $\mathbf{n}^{\mathbf{0}} \mathbf{1 2}$, de 5 de Setembro de 2008 , $2008 b$.

MINISTÉRIO DA EDUCAÇÃO; CONSELHO NACIONAL DE EDUCAÇÃO. Parecer CNE/CES n 776/97, 1997. 